\title{
Exposure to household furry pets influences the gut microbiota of infants at 3-4 months following various birth scenarios
}

Hein M. Tun ${ }^{1}$, Theodore Konya ${ }^{2}$, Tim K. Takaro ${ }^{3}$, Jeffrey R. Brook², Radha Chari ${ }^{4}$, Catherine J. Field ${ }^{5}$, David S. Guttman ${ }^{6}$, Allan B. Becker ${ }^{7}$, Piush J. Mandhane ${ }^{1}$, Stuart E. Turvey ${ }^{8}$, Padmaja Subbarao ${ }^{9}$, Malcolm R. Sears ${ }^{10}$, James A. Scott ${ }^{2}$, Anita L. Kozyrskyj ${ }^{*}$ and the CHILD Study Investigators

\begin{abstract}
Background: Early-life exposure to household pets has the capacity to reduce risk for overweight and allergic disease, especially following caesarean delivery. Since there is some evidence that pets also alter the gut microbial composition of infants, changes to the gut microbiome are putative pathways by which pet exposure can reduce these risks to health. To investigate the impact of pre- and postnatal pet exposure on infant gut microbiota following various birth scenarios, this study employed a large subsample of 746 infants from the Canadian Healthy Infant Longitudinal Development Study (CHILD) cohort, whose mothers were enrolled during pregnancy between 2009 and 2012. Participating mothers were asked to report on household pet ownership at recruitment during the second or third trimester and 3 months postpartum. Infant gut microbiota were profiled with 165 rRNA sequencing from faecal samples collected at the mean age of 3.3 months. Two categories of pet exposure (i) only during pregnancy and (ii) pre- and postnatally were compared to no pet exposure under different birth scenarios.

Results: Over half of studied infants were exposed to at least one furry pet in the prenatal and/or postnatal periods, of which $8 \%$ were exposed in pregnancy alone and $46.8 \%$ had exposure during both time periods. As a common effect in all birth scenarios, pre- and postnatal pet exposure enriched the abundance of Oscillospira and/or Ruminococcus $(P<0.05)$ with more than a twofold greater likelihood of high abundance. Among vaginally born infants with maternal intrapartum antibiotic prophylaxis exposure, Streptococcaceae were substantially and significantly reduced by pet exposure $(P<0.001$, FDRp $=0.03)$, reflecting an $80 \%$ decreased likelihood of high abundance $(\mathrm{OR} 0.20,95 \% \mathrm{Cl}, 0.06-0.70)$ for pet exposure during pregnancy alone and a $69 \%$ reduced likelihood (OR 0.31, 95\% $\mathrm{Cl}, 0.16-0.58)$ for exposure in the pre- and postnatal time periods. All of these associations were independent of maternal asthma/allergy status, siblingship, breastfeeding exclusivity and other home characteristics.
\end{abstract}

Conclusions: The impact of pet ownership varies under different birth scenarios; however, in common, exposure to pets increased the abundance of two bacteria, Ruminococcus and Oscillospira, which have been negatively associated with childhood atopy and obesity.

Keywords: Pets, Infant gut microbiota, Birth, Prenatal, Postnatal

\footnotetext{
* Correspondence: kozyrsky@ualberta.ca

'Department of Pediatrics, University of Alberta, 3-527 Edmonton Clinic

Health Academy, 11405-87th Avenue, Edmonton, AB T6G IC9, Canada

Full list of author information is available at the end of the article
} 


\section{Background}

Microbial colonization of the infant gastrointestinal tract is an essential process in our life cycle, and microbiotahost interactions during this developmental stage of life have a significant influence on future health. Following birth, the gut microbiota of newborns is characterized by low diversity, dominated by facultative anaerobes such as the Proteobacteria, after which the diversity of strict anaerobes within the Firmicutes and Bacteroidetes phyla increases towards an adult-like profile by 1 year of age [1-3]. Throughout this development, microbial composition is shaped by a number of factors including gestational age, mode of delivery (vaginal vs. caesarean), infant diet (breast milk vs. formula) and antibiotic treatment (direct vs. indirect via mother) [4, 5]. Among several environmental determinants that influence postnatal gut microbial development, rising rates of pet ownership globally have stimulated interest on the impact of household furry pets.

The notion that pets provide an immune benefit to human health stems from the hygiene hypothesis, first proposed by David Strachan in 1989 [6] and subsequently supported by several epidemiological studies [7-12], which attributes risk of allergic disease to overly hygienic environments. With further evidence that gut microbial dysbiosis during infancy is associated with the development of allergic disease, this notion has been revised as the 'microbiota hypothesis' [13]. Despite rapid microbial colonization of the gut after birth, environmental microbes in the antenatal and/or early postnatal period represent a critical exposure for early-life immune programming that may have long-term consequences. A pooled analysis of 7000 households documented that dog ownership during the first 2 years of life reduced sensitization to allergens in early childhood, although the evidence for asthma prevention was less clear [14]. In a meta-analysis of six studies that evaluated prenatal exposure to household pets, a lowered risk for allergic disease (atopic dermatitis, asthma) in offspring was found, especially for prenatal dog ownership [10]. Havstad et al. [15] documented lowered IgE levels until 2 years of age following pet exposure during pregnancy, which were not altered by postnatal pet ownership. Further, the prenatal pet association was strongest for children born by caesarean section (CS). Still others have found that postnatal pet ownership modified earlylife risk factors for metabolic diseases. In the absence of household pets, Cassidy-Bushrow et al. [16] reported a twofold higher risk of obesity at the age of 2 in CSdelivered infants compared to those born vaginally. However, no association was found between CS delivery and toddler obesity in the presence of pet ownership.

In a pilot study of 24 infants, our group observed higher microbial richness and diversity of the infant gut in the presence of household pets at 3 months of age with under-representation of Bifidobacteriaceae and overrepresentation of Peptostreptococcaceae [17]. Nermes et al. [11] found counts of Bifidobacterium breve to be lower but Bifidobacterium longum to be higher in non-wheezing infants exposed to pets. In their subsequent analysis [18], pet-exposed infants harboured more animal-specific Bifidobacterium pseudolongum, indicating the bacterial transfer from pets to infants. Moreover, our previous findings also highlighted that pets can alter house dust microbiota [19]. This study is a follow-up to our previous pilot study, undertaking an evaluation of the influence of household pets on faecal microbial composition at 3-4 months after birth in a large subsample of 746 infants from the Canadian Healthy Infant Longitudinal Development (CHILD) national population-based birth cohort. In this study, we aimed to determine the existence of gut microbial associations with prenatal and/or postnatal pet exposures under different scenarios, independent of siblingship and other covariates.

\section{Methods \\ Study design}

This study involved a subsample of 804 infants from three study sites (Edmonton, Vancouver and Winnipeg) of the CHILD cohort (www.canadianchildstudy.ca). Mothers of the studied infants were enrolled during pregnancy between 2009 and 2012. The mothers were asked about pet ownership in a standardized questionnaire at recruitment in the second or third trimester of pregnancy and 3 months postpartum. Microbiota analysis was performed on faecal samples collected from infants at 3-4 months, with complete pre- and postnatal pet exposure data $(n=753)$. A pet exposure variable denoting four mutually exclusive categories was created as follows: (1) no pet exposure in the pre- or postnatal periods, (2) only prenatal pet exposure, (3) both pre- and postnatal pet exposure and (4) only postnatal pet exposure (Fig. 1a). Due to the limited number of infants $(n=7)$ in the fourth category, we excluded that category from the analysis, leaving 746 with complete data for subsequent analysis. Table 1 shows demographic characteristics of the studied infants with differential pet exposure status. Data on other covariates were obtained from hospital records (mode of delivery, intrapartum antibiotic prophylaxis (IAP)) or from standardized questionnaires completed by mothers (maternal race, maternal asthma and allergy status during pregnancy, type of home, size of household, type of floor, presence of siblings, breastfeeding status and infant antibiotic exposure before 3 months). Written informed consent was obtained from parents 


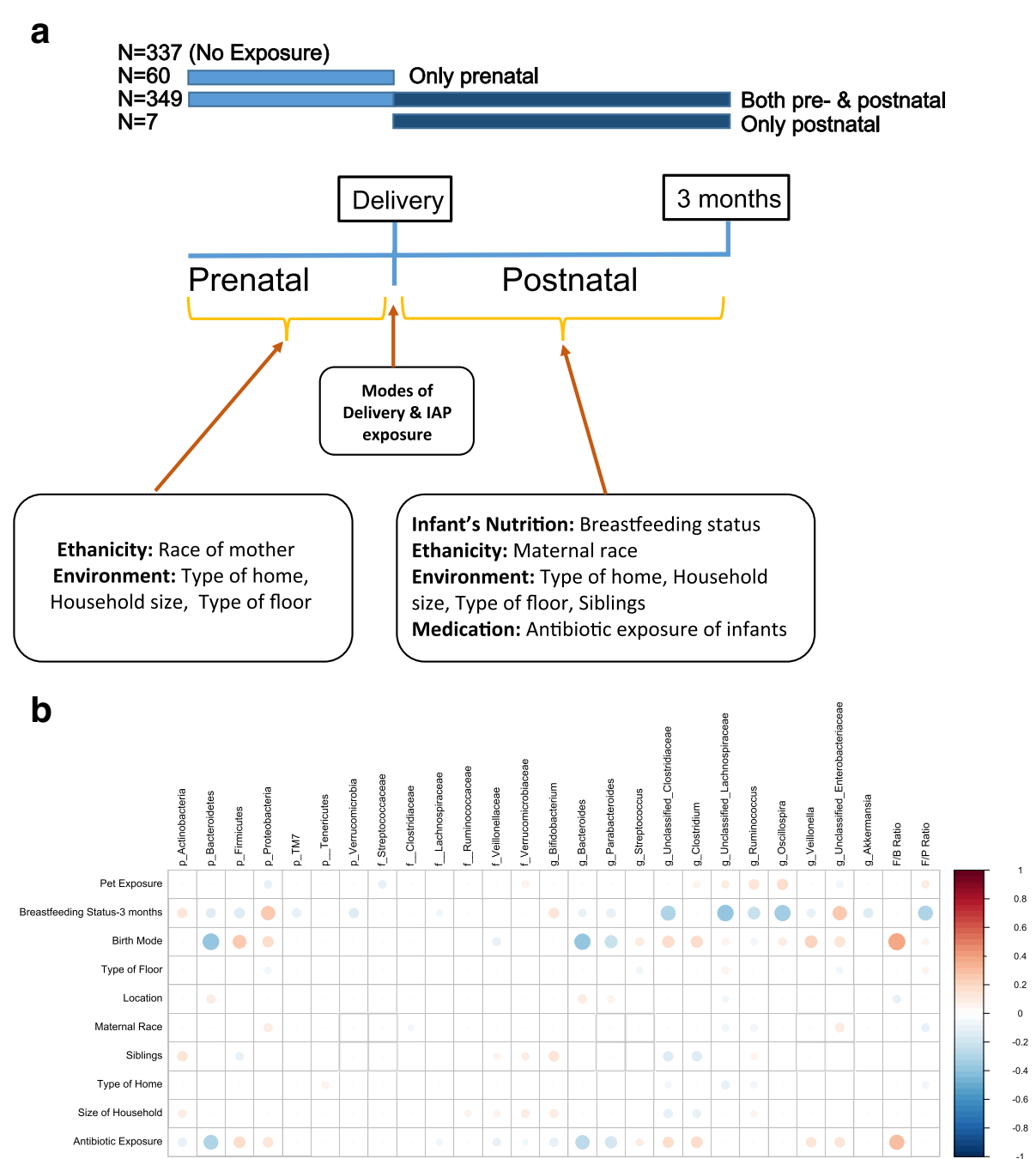

Fig. 1 a Pet exposure and other covariates (at prenatal and postnatal) that influence the infant gut microbiota. b General impact of pet exposure and other covariates on gut microbiota measurements of infants at 3-4 months. Circle sizes and colour intensity represent the magnitude of correlation. Red circles = positive correlations; blue circles = negative correlations. Antibiotic exposure of infants was collective consideration of both indirect exposure (maternal IAP) and direct exposure (IV and oral antibiotics)

at enrollment. This study was approved by the ethics board at the University of Alberta.

\section{Faecal microbiota analysis}

Faecal samples of infants were collected at the mean age of 3.34 months (range 2.7-4.3) using a standard protocol during a planned home visit. Methods of sample collection, DNA extraction and amplification, 16S rRNA sequencing and taxonomic classification have been previously described $[20,21]$. Briefly, samples were refrigerated immediately after collection and during transport and stored at $-80^{\circ} \mathrm{C}$ until analysis. Genomic DNA was extracted from 80 to $200 \mathrm{mg}$ of stool using the QIAamp DNA Stool Mini kit (Qiagen, Venlo, the Netherlands). The V4 hypervariable region of the bacterial 16S rRNA gene was amplified by PCR using universal bacterial primers: V4-515f: 5' AAT GAT ACG GCG ACC ACC GAG ATC TAC ACT ATG GTA ATT GTG TGC CAG CMG CCG CGG TAA-3', V4-806r:5'-CAA GCA GAA GAC GGC ATA CGA GAT XXXXXXXXXXXX AGT CAG TCA GCC GGA CTA CHV GGG TWT CTA AT3 '. For sample multiplexing, reverse primers were barcoded uniquely for each sample (barcoded sequence was denoted in the primer sequence by Xs). Each $25 \mu \mathrm{l} \mathrm{PCR}$ mixture contained $12.5 \mu \mathrm{l}$ 2x Kapa2G Hotstart mix (Kapa Biosystems, Wilmington, MA), $0.6 \mu \mathrm{M}$ of both forward and reverse primers and $2 \mu \mathrm{l}$ genomic DNA $(5 \mathrm{ng} / \mu \mathrm{l})$. PCR amplification consisted of an initial denaturation step for $3 \mathrm{~min}$ at $94{ }^{\circ} \mathrm{C}$, followed by 20 cycles of denaturation for $30 \mathrm{~s}$ at $94{ }^{\circ} \mathrm{C}$, annealing for $30 \mathrm{~s}$ at $50{ }^{\circ} \mathrm{C}$ and an extension step for $30 \mathrm{~s}$ at $72{ }^{\circ} \mathrm{C}$. PCR reactions for each sample were performed in triplicate with a negative control in 
Table 1 Population characteristics and associations with exposure to household pets

\begin{tabular}{|c|c|c|c|c|c|}
\hline & \multirow{2}{*}{$\begin{array}{l}\text { Overall } \\
N(\%) \\
746(100)\end{array}$} & \multicolumn{4}{|c|}{ Households with at least 1 furry pet } \\
\hline & & $\begin{array}{l}\text { No exposure } \\
N(\%) \\
337(45.2)\end{array}$ & $\begin{array}{l}\text { Only prenatal } \\
N(\%) \\
60(8.0)\end{array}$ & $\begin{array}{l}\text { Both pre- and postnatal } \\
N(\%) \\
349(46.8)\end{array}$ & $\begin{array}{l}P \text { value to } \\
\text { compare } 3 \text { exposure groups }\end{array}$ \\
\hline \multicolumn{6}{|l|}{ Birth mode } \\
\hline Vaginal, IAP- & $375(50.3)$ & $171(45.6)$ & $32(8.5)$ & $172(45.9)$ & \multirow[t]{4}{*}{0.88} \\
\hline Vaginal, IAP+ & $176(23.6)$ & $75(42.6)$ & $14(8.0)$ & $87(49.4)$ & \\
\hline Caesarean, scheduled & $87(11.7)$ & $42(48.3)$ & $4(4.6)$ & $41(47.1)$ & \\
\hline Caesarean, emergency & $108(14.5)$ & $49(45.4)$ & $10(9.3)$ & $49(45.4)$ & \\
\hline \multicolumn{6}{|l|}{ Study sites } \\
\hline Edmonton & $216(29.0)$ & $80(37.0)$ & $19(8.8)$ & $117(54.2)$ & \multirow[t]{3}{*}{$<0.001$} \\
\hline Vancouver & $286(38.3)$ & $158(55.2)$ & $16(5.6)$ & $112(39.2)$ & \\
\hline Winnipeg & $244(32.7)$ & 99 (40.6) & $25(10.2)$ & $120(49.2)$ & \\
\hline \multicolumn{6}{|l|}{ Maternal race } \\
\hline Caucasian & $561(75.3)$ & $223(39.8)$ & $49(8.7)$ & $289(51.5)$ & \multirow[t]{3}{*}{$<0.001$} \\
\hline Other & $78(10.5)$ & $38(48.7)$ & $5(6.4)$ & $35(44.9)$ & \\
\hline Asian & $106(14.2)$ & $76(71.7)$ & $6(5.7)$ & $24(22.6)$ & \\
\hline \multicolumn{6}{|c|}{ Maternal asthma during pregnancy } \\
\hline No & $675(90.6)$ & $307(45.5)$ & $53(7.9)$ & $315(46.7)$ & \multirow[t]{2}{*}{0.98} \\
\hline Yes & $70(9.4)$ & $31(44.3)$ & $6(8.6)$ & $33(47.1)$ & \\
\hline \multicolumn{6}{|c|}{ Maternal allergy during pregnancy } \\
\hline No & $271(36.6)$ & $133(49.1)$ & $24(8.9)$ & $114(42.1)$ & \multirow[t]{2}{*}{0.19} \\
\hline Yes & $470(63.4)$ & $204(43.4)$ & $36(7.7)$ & $230(48.9)$ & \\
\hline \multicolumn{6}{|l|}{ Type of home } \\
\hline Single (house) & $592(79.4)$ & $251(42.4)$ & $53(9.0)$ & $288(48.6)$ & \multirow[t]{2}{*}{0.007} \\
\hline Multiple (condo/apartment) & $154(20.6)$ & $86(55.8)$ & $7(4.5)$ & $61(39.6)$ & \\
\hline \multicolumn{6}{|l|}{ Size of household $<3$} \\
\hline No & $414(55.5)$ & $190(45.9)$ & $34(8.2)$ & $190(45.9)$ & \multirow[t]{2}{*}{0.86} \\
\hline Yes & $332(44.5)$ & $147(44.3)$ & $26(7.8)$ & $159(47.9)$ & \\
\hline \multicolumn{6}{|c|}{ Changed house (from 18 weeks of pregnancy to 3 months) } \\
\hline No & $683(91.6)$ & $309(45.2)$ & $51(7.5)$ & $323(47.3)$ & \multirow[t]{2}{*}{0.15} \\
\hline Yes & $63(8.4)$ & $28(44.4)$ & $9(14.3)$ & $26(41.3)$ & \\
\hline \multicolumn{6}{|l|}{ Type of floor } \\
\hline Not carpeted & $360(48.3)$ & $156(43.3)$ & $25(6.9)$ & $179(49.7)$ & \multirow[t]{3}{*}{0.58} \\
\hline Partially carpeted & $235(31.5)$ & $110(46.8)$ & $21(8.9)$ & $104(44.3)$ & \\
\hline Completely carpeted & $151(20.2)$ & $71(47.0)$ & $14(9.3)$ & $66(43.7)$ & \\
\hline Siblings & & & & & \\
\hline No & $379(52.6)$ & $162(42.7)$ & $28(7.4)$ & 189 (49.9) & 0.21 \\
\hline Yes & $342(47.4)$ & $166(48.5)$ & $28(8.2)$ & $148(43.3)$ & \\
\hline Antibiotic exposure (0-3 month & & & & & \\
\hline No & $317(43.8)$ & $142(44.8)$ & $26(8.2)$ & $149(47.0)$ & 0.98 \\
\hline Yes & $407(56.2)$ & $184(45.2)$ & $32(7.9)$ & $191(46.9)$ & \\
\hline Breastfeeding status at 3 montl & & & & & \\
\hline No & $126(16.9)$ & $46(36.5)$ & $14(11.1)$ & $66(52.4)$ & 0.17 \\
\hline Partial & $229(30.7)$ & $101(44.1)$ & $18(7.9)$ & $110(48.0)$ & \\
\hline Exclusive & $391(52.4)$ & $190(48.6)$ & $28(7.2)$ & $173(44.2)$ & \\
\hline
\end{tabular}

Comparisons by chi-square test

antibiotic exposure of infants = collective consideration of both indirect exposure (maternal IAP) and direct exposure (IV and oral antibiotics) 
each run. One hundred nanograms of pooled PCR product from each sample was concentrated using an Amicon Ultra-4 $30 \mathrm{~K}$ centrifugal filter (Millipore, Billerica, MA, USA), run on a $1.4 \%$ agarose gel, extracted and cleaned with the GENE-CLEAN Turbo Kit (MP Biomedicals Inc, Solon, OH, USA).

Pooled PCR amplicons were subjected to paired-end sequencing by Illumina Miseq platform. Using a QIIME pipeline (v1.6.0, qiime.org) [22], forward and reverse reads were assembled using PandaSeq for a final length of $144 \mathrm{bp}$ (unassemblable sequences discarded), demultiplexed and filtered against the GREENGENES reference database (v13.8) [23] to remove all sequences with $<60 \%$ similarity. Remaining sequences were clustered with Usearch61 at 97\% sequence similarity against the GREENGENES database (closed picking algorithm), and taxonomic assignment was achieved using the RDP classifier [24] constrained by GREENGENES. After taxonomic assignment, operational taxonomic units (OTUs) representing bacterial origin were selected, and bacterial OTUs with overall relative abundance below 0.0001 were excluded from subsequence for downstream analyses. To avoid the bias due to variation in sequencing depths among samples, data were rarefied to 13,000 sequences per sample.

\section{Statistical analysis}

With the recommended pipeline in QIIME, relative abundance of bacterial OTUs was summarized at the phylum, family and genus levels. Microbial alpha diversity within samples was calculated with three standard indices (Chao1, Shannon and Simpson). Microbial community differences between samples (beta diversity) were examined by the permutational multivariate analysis of variance (PERMANOVA) comparison of unweighted UNIFRAC distance matrices, with 1000 permutations. Spearman correlation analyses were performed to address associations between pet exposure, other covariates and microbiota measures, and illustrated using the $\mathrm{R}$ package corrplot. Median richness, diversity and relative abundance of dominant taxonomic groups were compared by non-parametric Kruskal-Wallis (KW) test, followed by post hoc comparisons between non-exposed and pet exposure groups using the Mann-Whitney $U$ test. As shown in previous reports $[20,25]$, ratios of specific taxa are commonly evaluated due to the co-existence nature of gut microbiota. We evaluated three ratios: Firmicutes to Bacteroidetes (F/B) ratio, Firmicutes to Proteobacteria (F/P) ratio and Enterobacteriaceae to Bacteroidaceae (E/B) ratio. Since caesarean birth and maternal IAP are major microbiota disruption exposures [21], we performed our analyses within four different birth scenarios for infants born: (1) vaginally without IAP, (2) vaginally with IAP, (3) by scheduled CS and (4) by emergency CS. To restrict the effects of siblingship and exclusively breastfeeding, comparisons were conducted for specific groups with or without siblings, non-exclusively breastfed infants, as well as non-exclusively breastfed infants without siblings. Independent associations between microbiota abundance and pet exposure were tested by multiple variable logistic regression, with microbiota measures categorised as above and below the median.

To identify discriminative taxonomic biomarkers, the linear discriminant analysis effect size (LEfSE) was determined with a LDA log score cut-off of 2, followed by the Kruskal-Wallis test with the Dunn's multiple comparison test, using no pet exposure as the reference group. Excluded were infants from non-Caucasian mothers, those with direct antibiotic exposure from birth to 3 months of age and infants exclusively breastfed.

\section{Results}

Study population and exposures to household furry pets In this population cohort of 746 infants, less than half of households had no pets $(45.2 \%, n=337), 8 \%(n=60)$ of households owned pets only during the index pregnancy ( $48.3 \%$ dog only, $36.1 \%$ cat only, $8.3 \%$ both dog and cat, and $7.3 \%$ other furry pets $)$ and $46.8 \%(n=349)$ owned furry pets both in the pregnancy and postnatal time periods $(44.1 \%$ dog only, $33.8 \%$ cat only, $20.1 \%$ both dog and cat, $2 \%$ other furry pets). Table 1 shows household characteristics for each pet exposure category. Significant differences by pet ownership were found according to study location $(P<0.001)$, maternal race $(P<0.001)$ and type of home $(P=0.007)$.

\section{Overall community structure of gut microbiota, diversity and richness of gut microbiota}

Significant microbial community differences were detected by PERMANOVA by prenatal (pseudo $F=2.03, P$ $=0.001$ ), as well as pre- and postnatal exposures (pseudo $F=1.51, P=0.005)$ in all children. Under individual birth scenarios, the impact of any pet exposure was significant only for infants born by emergency CS (pseudo $F=2.02$, $P=0.001$ ) (Additional file 1: Table S1). Overall microbial richness of the infant gut and species richness within the Firmicutes phylum were significantly elevated with pet exposure during pregnancy alone (Additional file 2: Table S2). Upon stratification by birth mode, these trends remained but statistical significance was lost, except for species richness of Firmicutes in vaginally born infants without IAP exposure (Additional file 3: Table S3). Reduced species richness within the Proteobacteria phylum became more statistically significant among infants who were born vaginally without IAP exposure (especially for prenatal exposure alone) and who were born by emergency CS (for both pre- and postnatal exposure) (Additional file 3: Table S3). Although there was no 
significant impact on overall microbial diversity (Shannon index), pre- and postnatal pet exposure significantly increased the species richness (Chao1) and diversity (Shannon) within the Firmicutes phylum (Additional file 2: Table S2). After stratification by birth scenario, these trends were consistent but were not statistically significant (Additional file 3: Table S3).

\section{Taxonomic composition of gut microbiota Vaginal with no IAP}

Among the dominant phyla, Proteobacteria were underrepresented among infants born vaginally with no IAP when pets were present $(P=0.005$, FDRp $=0.07$, Table 2$)$. This reduced abundance was more prominent when pet exposure was solely prenatal, whereas the impact of preand postnatal pet ownership became more statistically significant in non-exclusively breastfed infants (Additional file 4: Table S4). In conjunction with depleted Proteobacterial abundance, significant increases to the Firmicutes/Proteobacteria $(\mathrm{F} / \mathrm{P})$ ratio were observed by pet exposure $(P=0.003$, FDRp $=0.05$, Table 2$)$. The impact of pre- and postnatal exposure on the $\mathrm{F} / \mathrm{P}$ ratio also became more significant in non-exclusively breastfed infants (Additional file 4: Table S4).

With prenatal pet exposure alone, there was a twofold odds for high abundance of Vellionellaceae and unclassified Lachnospiraceae; high $\mathrm{F} / \mathrm{P}$ ratios were also more likely (Fig. 2 and Additional file 5: Table S5). These microbiota associations were attenuated when exposure to furry pets continued in the postnatal period. Collectively, pre- and postnatal pet ownership was associated with 1.5-fold increases to high Firmicutes species richness in infants, and high abundance of Verrucomicrobiaceae and of genus Clostridium (Fig. 2 and Additional file 5: Table S5).

\section{Vaginal with IAP}

At the family level, median abundance of Streptococcaceae were substantially and significantly reduced by prenatal pet exposure $(P<0.001$, FDRp $=0.03$, Table 2$)$. However, the prenatal only association was attenuated in the absence of older siblings at home. Pre- and postnatal pet exposure also enriched the Bacteroidaceae, an elevation not seen in non-exclusively breastfed infants (Additional file 4: Table S4).

Twofold increases were found in the odds of high diversity within the Firmicutes and of high abundance with Bacteroidaceae. The E/B ratio was reduced by $53 \%$ (95\%CI 0.25-0.89) and high abundance of Streptococcaceae by almost one third (95\%CI $0.16-0.58)$ compared to infants without pet exposure in the pre- and postnatal time periods (Fig. 2 and Additional file 5: Table S5). High Streptococcaceae levels were also substantially less likely for infants exposed to pets only during pregnancy (unadjusted OR 0.20, 95\%CI 0.06-0.70) (Fig. 2 and Additional file 5: Table S5).

Following exposure to pets during pregnancy and postnatally, a rare member of Proteobacteria, genus Bilophila, was depleted after vaginal birth with maternal IAP and no exclusive breastfeeding $(P=0.02, \log$ LDA score of 3.5, Additional file 6: Table S6 and Additional file 7: Figure S1).

\section{Emergency CS}

Enrichment of the median abundance of Bifidobacteriaceae was observed in infants born by emergency CS with pet exposure $(P=0.003$, FDRp $=0.05$, Table 2$)$, an association which disappeared in non-exclusively breastfed infants (Additional file 4: Table S4). There was a substantial and significant link between prenatal pet exposure and high abundance of Bifidobacteriaceae (unadjusted OR 7.53, 95\%CI 1.44-39.50, Additional file 5: Table S5). Concurrently, high species richness within Proteobacteria and high levels of Enterobacteriaceae were much less likely to be present (Fig. 2 and Additional file 5: Table S5). When emergency CS was not followed by exclusive breastfeeding, the combined impact of pet exposure during pregnancy and postpartum was reduced abundance of the genus Citrobacter $(P=0.03$, log LDA score of 3.4$)$ and genus Lactococcus $(P=0.03, \log$ LDA score of 2.5, Additional file 6: Table S6 and Additional file 7: Figure S1).

\section{All birth scenarios}

At the genus level, Ruminococcus and Oscillospira were over-represented in infants exposed to pets in all birth scenarios $(P<0.05)$ (Fig. $1 \mathrm{~b}$ and Table 3$)$. With the exception of vaginal birth with no IAP, these associations were less statistically significant among infants with non-exclusive breastfeeding (Additional file 8: Table S7). Prenatal pet exposure alone was associated with high abundance of Ruminococcus (unadjusted OR 2.98, 95\%CI 1.30-6.81) and Oscillospira (unadjusted OR 2.56, 95\%CI 1.19-5.53, Fig. 2 and Additional file 5: Table S5) following vaginal birth with no IAP. Associations with genus Oscillospira were unchanged with continuing pet exposure in these infants. More than twofold increases in the odds for high abundance of Ruminococcus (unadjusted OR 2.43, 95\%CI 1.29-4.59) were also observed following IAP in vaginal birth. In a subgroup of these IAP-exposed infants who were not exclusively breastfed afterwards, the Ruminococcaceae population was significantly enriched by prenatal pet exposure alone $(P=$ 0.002 , and $\log$ LDA score of 4.2, Additional file 6: Table S6 and Additional file 7: Figure S1).

Among the few associations found in infants delivered by scheduled CS, a threefold likelihood in high abundance of 
Table 2 Relative abundance of dominant phyla and families in faecal microbiota of infants at 3-4 months, according to birth scenarios and pet exposure

\begin{tabular}{|c|c|c|c|c|c|c|}
\hline \multirow[t]{2}{*}{ Birth scenarios } & \multirow[t]{2}{*}{ Dominant taxa $a^{a}$} & \multirow[b]{2}{*}{$\begin{array}{l}\text { No exposure } \\
337(45.2 \%) \\
\text { Median (IQR) }\end{array}$} & \multicolumn{4}{|c|}{ Pet exposure status $(N=746)$} \\
\hline & & & $\begin{array}{l}\text { Only prenatal } \\
60(8.0 \%) \\
\text { Median (IQR) }\end{array}$ & $\begin{array}{l}\text { Both pre- and postnatal } \\
349(46.8 \%) \\
\text { Median (IQR) }\end{array}$ & $P$ & FDRp \\
\hline \multirow[t]{19}{*}{ Vaginal, IAP- } & & $171(45.6 \%)$ & $32(8.5 \%)$ & $172(45.9 \%)$ & & \\
\hline & Actinobacteria & $6.7(2.4-16.1)$ & $4.3(1.3-13.2)$ & $7.2(1.8-18.9)$ & 0.29 & 0.84 \\
\hline & Bifidobacteriaceae & $5.4(1.3-14.6)$ & $5.2(0.3-14.8)$ & $4.9(0.99-13.6)$ & 0.96 & 0.96 \\
\hline & Bacteroidetes & $38.6(2.0-6.9)$ & $37.7(2.5-73.9)$ & $35.2(0.87-67.0)$ & 0.71 & 0.88 \\
\hline & Bacteroidaceae & $18.1(0.09-58.4)$ & $1.28(0.07-35.84)$ & $7.6(0.07-54.32)$ & 0.41 & 0.88 \\
\hline & Porphyromonadaceae & $0.01(0.00-0.13)$ & $0.01(0.00-0.60)$ & $0.01(0.00-0.15)$ & 0.92 & 0.95 \\
\hline & Firmicutes & $17.3(5.5-32.3)$ & $22.9(10.1-40.3)$ & $16.2(7.9-32.3)$ & 0.44 & 0.88 \\
\hline & Streptococcaceae & $0.65(0.21-1.8)$ & $1.1(0.23-2.8)$ & $0.57(0.18-1.9)$ & 0.59 & 0.88 \\
\hline & Clostridiaceae & $0.33(0.02-2.1)$ & $0.35(0.09-1.8)$ & $0.45(0.06-2.9)$ & 0.52 & 0.88 \\
\hline & Lachnospiraceae & $2.6(0.03-9.4)$ & $4.7(0.16-12.3)$ & $2.2(0.04-10.4)$ & 0.59 & 0.88 \\
\hline & Rumminococcaceae & $0.09(0.00-1.10)$ & $0.62(0.00-2.5)$ & $0.05(0.00-1.7)$ & 0.55 & 0.88 \\
\hline & Vellionellaceae & $4.4(0.48-17.2)$ & $9.7(3.4-17.7)$ & $6.2(1.2-20.3)$ & 0.17 & 0.72 \\
\hline & Proteobacteria & $17.6(9.7-37.4)$ & $7.2(2.0-28.6)^{* *}$ & $15.5(7.6-35.4)$ & 0.005 & 0.07 \\
\hline & Enterobacteriaceae & $17.0(6.5-37.8)$ & $12.0(3.9-47.0)$ & $14.7(4.8-37.7)$ & 0.61 & 0.88 \\
\hline & Verrucomicrobia & $0.00(0.00-0.01)$ & $0.00(0.00-0.01)$ & $0.00(0.00-0.01)$ & 0.36 & 0.88 \\
\hline & Verrucomicrobiaceae & $0.00(0.00-0.01)$ & $0.00(0.00-0.01)$ & $0.00(0.00-0.02)^{*}$ & 0.05 & 0.45 \\
\hline & F/B ratio & $0.47(0.1-6.2)$ & $0.58(0.15-12.6)$ & $0.57(0.15-23.3)$ & 0.67 & 0.88 \\
\hline & F/P ratio & $0.91(0.29-2.3)$ & $2.5(0.77-11.6)^{* * * *}$ & $1.0(0.39-3.4)$ & 0.003 & 0.05 \\
\hline & E/B ratio & $0.84(0.15-353.7)$ & $21.0(0.12-333.7)$ & $1.3(0.12-487.6)$ & 0.92 & 0.95 \\
\hline \multirow[t]{19}{*}{ Vaginal, IAP+ } & & 75 (42.6\%) & $14(8.0 \%)$ & $87(49.4 \%)$ & & \\
\hline & Actinobacteria & $2.1(0.24-10.9)$ & $2.7(0.52-4.4)$ & $4.0(0.56-17.8)$ & 0.18 & 0.72 \\
\hline & Bifidobacteriaceae & $6.9(1.3-20.3)$ & 3.7 (1.7-10.9) & $3.6(1.4-14.5)$ & 0.69 & 0.88 \\
\hline & Bacteroidetes & $2.8(0.07-61.3)$ & $33.7(0.05-66.9)$ & $21.3(0.05-69.9)$ & 0.9 & 0.95 \\
\hline & Bacteroidaceae & $9.5(0.08-43.2)$ & $27.6(0.04-66.5)$ & $35.2(0.65-65.0)^{* *}$ & 0.01 & 0.12 \\
\hline & Porphyromonadaceae & $0.01(0.00-0.28)$ & $0.00(0.00-0.14)$ & $0.01(0.00-0.29)$ & 0.52 & 0.88 \\
\hline & Firmicutes & $20.7(8.2-53.4)$ & $21.1(5.3-57.9)$ & $17.1(7.4-46.7)$ & 0.89 & 0.95 \\
\hline & Streptococcaceae & $1.0(0.38-4.1)$ & $0.27(0.1-0.62)^{* *}$ & $0.43(0.2-0.97)^{* * *}$ & $<0.001$ & 0.03 \\
\hline & Clostridiaceae & $0.49(0.02-2.7)$ & $0.36(0.1-5.1)$ & $0.29(0.03-2.0)$ & 0.73 & 0.88 \\
\hline & Lachnospiraceae & $1.8(0.07-10.1)$ & $1.6(0.03-4.3)$ & $2.4(0.09-11.4)$ & 0.54 & 0.88 \\
\hline & Rumminococcaceae & $0.33(0.01-1.6)$ & $0.03(0.00-3.1)$ & $0.12(0.00-1.2)$ & 0.76 & 0.88 \\
\hline & Vellionellaceae & $6.7(0.7-18.3)$ & $2.6(0.41-34.4)$ & $3.0(0.56-11.1)$ & 0.32 & 0.85 \\
\hline & Proteobacteria & $22.9(11.3-42.5)$ & $26.7(10.9-52.1)$ & $15.3(4.5-40.1)$ & 0.06 & 0.48 \\
\hline & Enterobacteriaceae & $19.7(7.2-40.5)$ & $19.2(6.5-47.2)$ & $13.7(5.0-33.0)$ & 0.38 & 0.88 \\
\hline & Verrucomicrobia & $0.00(0.00-0.01)$ & $0.00(0.00-0.01)$ & $0.00(0.00-0.01)$ & 0.7 & 0.88 \\
\hline & Verrucomicrobiaceae & $0.00(0.00-0.01)$ & $0.00(0.00-0.00)$ & $0.00(0.00-0.01)$ & 0.74 & 0.88 \\
\hline & F/B ratio & $10.3(0.21-494.0)$ & $0.49(0.1-1333.3)$ & $1.8(0.15-819.4)$ & 0.96 & 0.96 \\
\hline & F/P ratio & $0.88(0.31-2.5)$ & $1.0(0.14-3.1)$ & $1.4(0.54-3.6)$ & 0.14 & 0.63 \\
\hline & E/B ratio & $1.7(0.23-460.4)$ & $2.5(0.16-1307.1)$ & $0.43(0.1-64.3)^{* *}$ & 0.02 & 0.21 \\
\hline \multirow[t]{3}{*}{ Caesarean, scheduled } & & $42(48.3 \%)$ & $4(4.6 \%)$ & 41 (47.1\%) & & \\
\hline & Actinobacteria & $5.3(0.89-23.2)$ & $4.7(0.58-20.9)$ & $9.1(2.4-17.1)$ & 0.63 & 0.88 \\
\hline & Bifidobacteriaceae & $11.3(3.1-17.0)$ & $0.04(0.02-17.1)$ & $8.3(2.4-19.5)$ & 0.26 & 0.78 \\
\hline
\end{tabular}


Table 2 Relative abundance of dominant phyla and families in faecal microbiota of infants at 3-4 months, according to birth scenarios and pet exposure (Continued)

\begin{tabular}{|c|c|c|c|c|c|c|}
\hline & Bacteroidetes & $0.13(0.04-0.62)$ & $30.1(0.1-61.2)$ & $0.11(0.05-0.66)$ & 0.58 & 0.88 \\
\hline & Bacteroidaceae & $8.0(0.06-63.1)$ & $3.6(0.03-28.3)$ & $3.9(0.11-52.7)$ & 0.56 & 0.88 \\
\hline & Porphyromonadaceae & $0.01(0.00-0.07)$ & $0.00(0.00-0.00)$ & $0.01(0.00-0.07)$ & 0.07 & 0.5 \\
\hline & Firmicutes & $31.2(13.3-55.0)$ & $8.5(4.5-31.2)$ & $39.2(16.1-52.8)$ & 0.12 & 0.63 \\
\hline & Streptococcaceae & $0.50(0.3-2.1)$ & $0.15(0.11-1.2)$ & $0.40(0.16-1.6)$ & 0.24 & 0.78 \\
\hline & Clostridiaceae & $0.77(0.05-4.4)$ & $3.9(0.43-16.4)$ & $0.64(0.09-2.6)$ & 0.74 & 0.88 \\
\hline & Lachnospiraceae & $2.1(0.05-10.2)$ & $5.0(0.81-28.5)$ & $1.7(0.05-8.3)$ & 0.71 & 0.88 \\
\hline & Rumminococcaceae & $0.08(0.01-1.8)$ & $3.5(0.16-9.5)$ & $0.05(0.00-2.5)$ & 0.41 & 0.88 \\
\hline & Vellionellaceae & $3.4(0.36-10.7)$ & $2.7(0.93-13.1)$ & $4.9(0.92-22.7)$ & 0.54 & 0.88 \\
\hline & Proteobacteria & $33.2(11.4-51.8)$ & $44.4(13.9-79.9)$ & $34.2(13.5-50.4)$ & 0.67 & 0.88 \\
\hline & Enterobacteriaceae & $16.1(8.9-35.7)$ & $25.6(15.9-73.1)$ & $21.8(8.0-47.1)$ & 0.46 & 0.88 \\
\hline & Verrucomicrobia & $0.00(0.00-0.01)$ & $0.00(0.00-0.00)$ & $0.00(0.00-0.01)$ & 0.33 & 0.85 \\
\hline & Verrucomicrobiaceae & $0.00(0.00-0.00)$ & $0.00(0.00-0.02)$ & $0.00(0.00-0.01)$ & 0.23 & 0.78 \\
\hline & F/B ratio & $169.0(22.8-859.8)$ & $18.2(0.07-1230.1)$ & $218(35.0-980.4)$ & 0.33 & 0.85 \\
\hline & F/P ratio & $1.2(0.35-3.1)$ & $0.41(0.12-0.75)$ & $1.1(0.6-3.1)$ & 0.13 & 0.63 \\
\hline & E/B ratio & $1.5(0.13-353.6)$ & $287(3.4-907.5)$ & $4.3(0.19-214.4)$ & 0.57 & 0.88 \\
\hline Caesarean, emergency & & $49(45.4 \%)$ & $10(9.3 \%)$ & $49(45.4 \%)$ & & \\
\hline & Actinobacteria & $7.4(1.4-20.5)$ & $5.6(3.3-13.5)$ & $6.1(0.4-16.9)$ & 0.72 & 0.88 \\
\hline & Bifidobacteriaceae & $3.5(0.08-7.0)$ & $28.8(12.7-71.9)^{* * *}$ & $3.4(0.57-18.1)$ & 0.003 & 0.05 \\
\hline & Bacteroidetes & $0.10(0.03-0.23)$ & $0.15(0.1-50.6)$ & $0.10(0.05-1.3)$ & 0.14 & 0.63 \\
\hline & Bacteroidaceae & $31.2(0.07-66.7)$ & $0.19(0.08-22.1)$ & $5.0(0.07-67.1)$ & 0.77 & 0.88 \\
\hline & Porphyromonadaceae & $0.01(0.00-0.14)$ & $0.00(0.00-0.13)$ & $0.01(0.00-0.04)$ & 0.19 & 0.72 \\
\hline & Firmicutes & $33.3(19.6-55.1)$ & $48.1(15.1-67.3)$ & $33.9(17.5-59.5)$ & 0.74 & 0.88 \\
\hline & Streptococcaceae & $0.59(0.15-1.5)$ & $3.5(1.7-6.8)^{* *}$ & $0.58(0.21-1.1)$ & 0.003 & 0.05 \\
\hline & Clostridiaceae & $0.38(0.04-7.5)$ & $0.17(0.01-3.1)$ & $0.70(0.02-3.7)$ & 0.64 & 0.88 \\
\hline & Lachnospiraceae & $2.9(0.05-7.3)$ & $3.8(0.05-5.7)$ & $1.6(0.26-9.1)$ & 0.77 & 0.88 \\
\hline & Rumminococcaceae & $0.14(0.00-2.6)$ & $0.01(0.01-0.91)$ & $0.08(0.00-0.58)$ & 0.25 & 0.78 \\
\hline & Vellionellaceae & $3.8(0.56-10.9)$ & $2.3(0.2-4.8)$ & $2.2(0.41-13.0)$ & 0.6 & 0.88 \\
\hline & Proteobacteria & $36.7(19.3-56.4)$ & $27.8(12.6-38.2)$ & $22.0(7.7-51.5)^{*}$ & 0.08 & 0.52 \\
\hline & Enterobacteriaceae & $20.3(6.3-40.1)$ & $10.2(5.7-55.2)$ & $15.0(8.1-43.1)$ & 0.88 & 0.95 \\
\hline & Verrucomicrobia & $0.00(0.00-0.01)$ & $0.00(0.00-0.01)$ & $0.00(0.00-0.01)$ & 0.81 & 0.91 \\
\hline & Verrucomicrobiaceae & $0.00(0.00-0.01)$ & $0.01(0.00-0.02)$ & $0.00(0.00-0.01)$ & 0.14 & 0.63 \\
\hline & F/B ratio & $281(52.7-1092.0)$ & $362(0.23-777.5)$ & 252 (10.9-910.5) & 0.63 & 0.88 \\
\hline & F/P ratio & $1.2(0.47-2.8)$ & $1.4(0.65-4.1)$ & $1.8(0.65-4.6)$ & 0.22 & 0.78 \\
\hline & E/B ratio & $0.84(0.09-480.7)$ & $4.3(0.7-322.8)$ & $10.0(0.13-336.3)$ & 0.87 & 0.95 \\
\hline
\end{tabular}

$I Q R$ interquartile range, F/B Firmicutes/Bacteroidetes, F/P Firmicutes/Proteobacteria, E/B Enterobacteriaceae/Bacteroidaceae, FDR false discovery rate Post hoc comparisons between no exposure group and either group of exposure were done by Mann-Whitney $U$ test. ${ }^{*} P<0.05 ;{ }^{* *} P<0.01 ;{ }^{* * *} P<0.0001$ ${ }^{a}$ Dominant taxa have overall median relative abundance $>1 \%$ at $-3-4$ months; phyla are in the plain text and families are italicized. Comparisons by nonparametric Kruskal-Wallis test with FDR correction for multiple testing

Oscillospira (95\%CI 1.27-7.67) was observed with combined prenatal and postnatal pet exposure. High levels of both genus Oscillospira (unadjusted OR 3.54, 95\%CI 1.548.14) and genus Ruminococcus (unadjusted OR 2.53, 95\%CI 1.11-5.75) were more likely among infants born via emergency CS. In the absence of exclusive breastfeeding after emergency CS, unclassified Ruminococcaceae were significantly enriched $(P=0.03, \log$ LDA score of 4.0 , Additional file 6: Table S6 and Additional file 7: Figure S1).

\section{Independence from covariates}

To test independence of associations between pet exposure and high microbial diversity, high abundance of microbes and their ratios, we conducted adjusted 

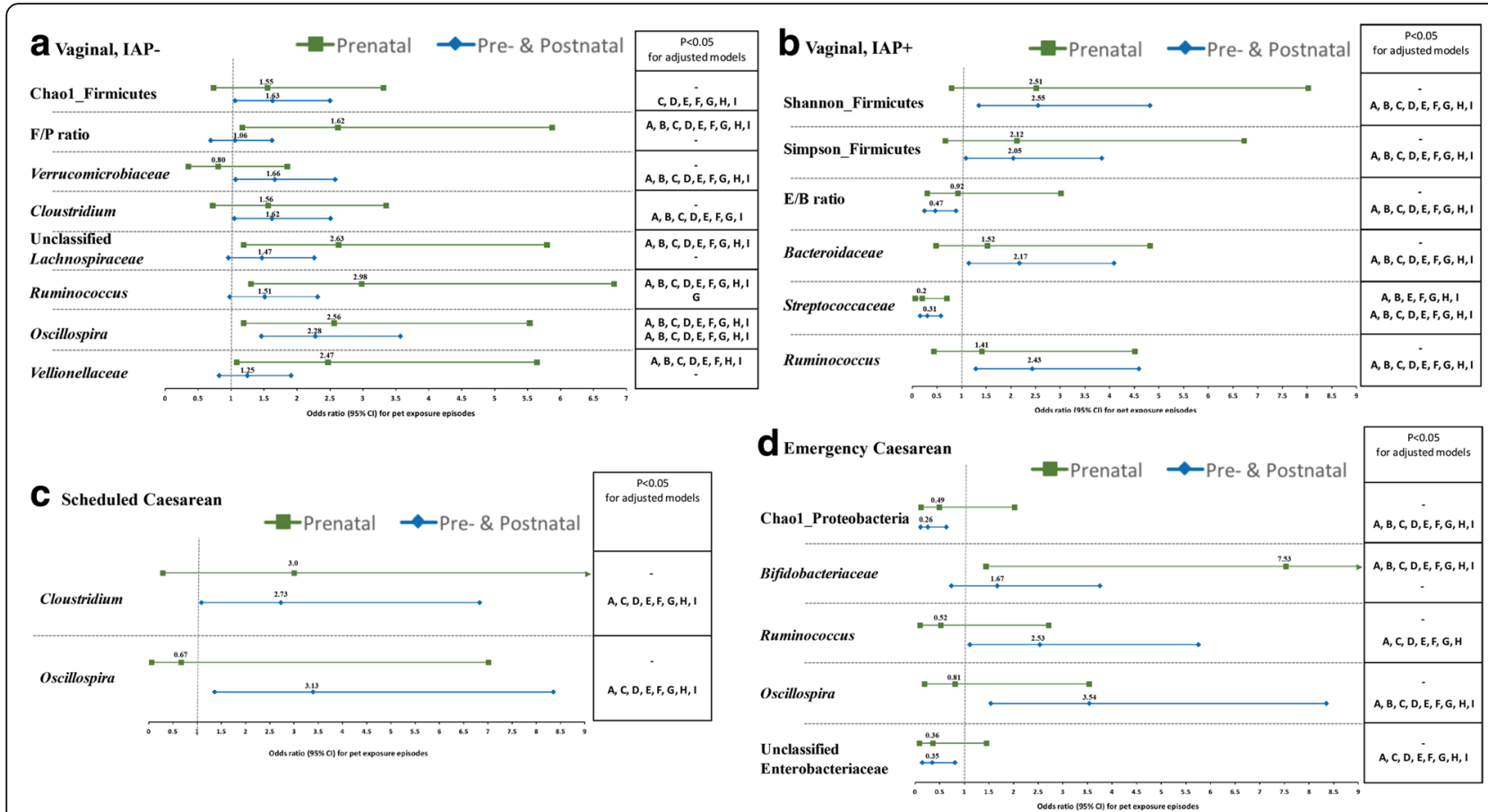

Fig. 2 Likelihoods of infant gut microbiota measures at 3-4 months according to pet exposure (parental alone vs. both pre- and postnatal) and various birth scenarios (a Vaginal, IAP-, b Vaginal, IAP+, c Shecduled Caesarean, and d Emergency Caesarean), with individual adjustments for potential confounding variables: Model A: Iocation, B: Maternal race, C: Maternal asthma and D: maternal allergy during pregnancy, E: Type of home, F: Moving home, G: Siblingship, H: Antibiotic exposure, and I: Breastfeeding status

logistic regression (Fig. 2 and Additional file 5: Table S5). Sequential adjustment for potential confounding variables (Table 1) such as study location, maternal race, maternal history of allergy and asthma during pregnancy, type of home, siblingship, antibiotic exposure and breastfeeding status at 3 months showed that associations between pet ownership and infant gut microbiota were generally robust and independent of these early-life events and environmental exposures. Some associations were moderately attenuated with adjustment, especially for breastfeeding status, maternal race and siblingship (Fig. 2 and Additional file 5: Table S5).

\section{Discussion}

In this general population cohort of 746 Canadian infants, we observed higher overall species richness and changes to taxon abundance in gut microbiota of infants exposed to furry pets during pregnancy or continuing to the postnatal period. These findings are in agreement with our previous report [17] of postnatal pet exposure on 3-month gut microbiota but not with studies in later infancy [26]. Moreover, elevations in microbial species richness in this study were evident with prenatal pet exposure. Since several studies including our own within the same cohort have reported low microbiota richness in early life to be associated with food sensitization and other atopic diseases $[20,27,28]$, higher microbial richness with prenatal pet exposure may confer protection against the development of atopy.

Our study revealed that pet exposure significantly increased species richness in the phylum Firmicutes, composed of families like the Clostridiaceae, Lachnospiraceae and Ruminococcaceae. These families of the Firmicutes are obligate anaerobes which reduce the oxidative state of the gut [29]; they are common constituents of the gut microbiota of healthy infants and severely depleted in malnourished infants [30]. In particular, we found Ruminococcus, or Oscillospira, belonging to the Ruminococcaceae, to be more abundant (median levels and levels above the median) among infants exposed to pets pre- and postnatally across all birth scenarios. Associations with ruminococcal abundance above the median were independent of all covariates, but attenuated after adjustment for breastfeeding status and maternal race. Prenatal pet exposure alone was sufficient to produce associations with Ruminococcus or Oscillospira, even under conditions of undisturbed gut microbiota following vaginal birth and no IAP. Of note, enrichment in faecal Oscillospira was among the few changes observed for pet ownership within infants delivered by scheduled CS.

Oscillospira is an enigmatic bacterium which has never been isolated in culture, but has been detected by $16 \mathrm{~S}$ rRNA gene surveys of the human microbiome in 
Table 3 Relative abundance of dominant genera in faecal microbiota of infants at 3-4 months, according to birth scenarios and pet exposure

\begin{tabular}{|c|c|c|c|c|c|c|}
\hline \multirow[t]{2}{*}{ Birth scenarios } & \multirow[t]{2}{*}{ Dominant genera $^{a}$} & \multicolumn{5}{|c|}{ Pet exposure status $(N=746)$} \\
\hline & & $\begin{array}{l}\text { No exposure } \\
337(45.17 \%) \\
\text { Median (IQR) }\end{array}$ & $\begin{array}{l}\text { Only prenatal } \\
60(8.0 \%) \\
\text { Median (IQR) }\end{array}$ & $\begin{array}{l}\text { Both pre- and postnatal } \\
349(46.78 \%) \\
\text { Median (IQR) }\end{array}$ & $P$ & FDRp \\
\hline \multirow{13}{*}{$\begin{array}{l}\text { Vaginal, } \\
\text { IAP- }\end{array}$} & & 171 (45.6\%) & $32(8.5 \%)$ & $172(45.9 \%)$ & & \\
\hline & Bifidobacterium & $5.3(1.8-14.9)$ & $2.2(0.68-13.0)$ & $6.3(1.6-17.8)$ & 0.21 & 0.63 \\
\hline & Bacteroides & $31.2(0.36-62.4)$ & $29.9(2.4-62.9)$ & $31.5(0.61-60.7)$ & 0.66 & 0.86 \\
\hline & Parabacteroides & $0.01(0.00-0.5)$ & $0.16(0.00-2.9)$ & $0.01(0.00-0.51)$ & 0.13 & 0.51 \\
\hline & Streptococcus & $0.62(0.13-2.1)$ & $0.46(0.21-1.4)$ & $0.59(0.21-1.8)$ & 0.81 & 0.86 \\
\hline & Unclassified Clostridiaceae & $0.03(0.00-0.45)$ & $0.09(0.00-0.46)$ & $0.07(0.01-0.49)$ & 0.45 & 0.81 \\
\hline & Clostridium & $0.01(0.00-0.38)$ & $0.01(0.00-0.29)$ & $0.02(0.00-0.42)$ & 0.15 & 0.51 \\
\hline & Unclassified Lachnospiraceae & $0.02(0.00-1.6)$ & $0.38(0.02-4.8)^{*}$ & $0.05(0.01-1.5)^{*}$ & 0.02 & 0.16 \\
\hline & Ruminococcus & $0.02(0.00-1.2)$ & $0.43(0.01-1.5)^{*}$ & $0.05(0.00-2.6)^{*}$ & 0.03 & 0.21 \\
\hline & Oscillospira & $0.00(0.00-0.04)$ & $0.07(0.00-2.3)^{*}$ & $0.01(0.00-0.7)^{* * *}$ & $<0.001$ & 0.04 \\
\hline & Veillonella & $1.5(0.16-14.9)$ & $2.9(0.13-9.1)$ & $1.6(0.24-7.6)$ & 0.89 & 0.91 \\
\hline & Unclassified Enterobacteriaceae & $15.5(7.0-31.9)$ & $5.4(1.3-28.4)^{* *}$ & $13.3(4.6-34.8)$ & 0.02 & 0.16 \\
\hline & Akkermansia & $0.00(0.00-0.01)$ & $0.00(0.00-0.01)$ & $0.00(0.00-0.01)$ & 0.42 & 0.81 \\
\hline \multirow{13}{*}{$\begin{array}{l}\text { Vaginal, } \\
\text { IAP+ }\end{array}$} & & $75(42.6 \%)$ & $14(8.0 \%)$ & 87 (49.4\%) & & \\
\hline & Bifidobacterium & $2.0(0.06-9.9)$ & $2.2(0.36-4.1)$ & $3.7(0.27-16.8)$ & 0.25 & 0.69 \\
\hline & Bacteroides & $0.67(0.05-59.2)$ & $33.7(0.04-56.3)$ & $12.0(0.05-69.6)$ & 0.84 & 0.88 \\
\hline & Parabacteroides & $0.01(0.00-0.03)$ & $0.00(0.00-1.12)$ & $0.00(0.00-0.02)$ & 0.95 & 0.95 \\
\hline & Streptococcus & $0.43(0.21-1.6)$ & $0.47(0.12-0.93)$ & $0.59(0.2-3.6)$ & 0.34 & 0.81 \\
\hline & Unclassified Clostridiaceae & $0.08(0.01-0.88)$ & $0.30(0.01-3.5)$ & $0.09(0.01-1.0)$ & 0.49 & 0.81 \\
\hline & Clostridium & $0.03(0.00-0.86)$ & $0.07(0.02-1.9)$ & $0.04(0.00-1.0)$ & 0.47 & 0.81 \\
\hline & Unclassified Lachnospiraceae & $0.02(0.00-3.8)$ & $0.66(0.01-4.1)$ & $0.08(0.01-3.2)$ & 0.55 & 0.83 \\
\hline & Ruminococcus & $0.01(0.00-0.44)$ & $0.02(0.00-1.28)$ & $0.03(0.01-1.88)^{* * *}$ & 0.004 & 0.1 \\
\hline & Oscillospira & $0.00(0.00-0.56)$ & $0.02(0.00-2.8)$ & $0.01(0.00-0.65)$ & 0.66 & 0.86 \\
\hline & Veillonella & $3.2(0.3-13.9)$ & $0.63(0.19-13.7)$ & $2.7(0.24-11.8)$ & 0.69 & 0.86 \\
\hline & Unclassified Enterobacteriaceae & $20.3(8.7-37.3)$ & $21.8(9.8-503)$ & $12.5(3.6-37.0)^{*}$ & 0.06 & 0.29 \\
\hline & Akkermansia & $0.00(0.00-0.01)$ & $0.00(0.00-0.01)$ & $0.00(0.00-0.01)$ & 0.74 & 0.86 \\
\hline \multirow[t]{13}{*}{ Caesarean, scheduled } & & $42(48.3 \%)$ & $4(4.6 \%)$ & 41 (47.1\%) & & \\
\hline & Bifidobacterium & $5.0(0.37-21.6)$ & $3.7(0.51-19.9)$ & $8.2(1.3-16.9)$ & 0.76 & 0.86 \\
\hline & Bacteroides & $0.08(0.04-0.44)$ & $30.0(0.08-61.1)$ & $0.10(0.05-0.42)$ & 0.49 & 0.81 \\
\hline & Parabacteroides & $0.00(0.00-0.01)$ & $0.00(0.00-0.04)$ & $0.00(0.00-0.01)$ & 0.74 & 0.86 \\
\hline & Streptococcus & $0.80(0.29-2.1)$ & $0.46(0.13-0.75)$ & $1.6(0.39-3.7)$ & 0.15 & 0.51 \\
\hline & Unclassified Clostridiaceae & $0.15(0.01-1.5)$ & $0.13(0.02-1.7)$ & $0.40(0.06-1.6)$ & 0.58 & 0.84 \\
\hline & Clostridium & $0.04(0.01-1.5)$ & $0.16(0.02-0.59)$ & $0.28(0.02-1.7)$ & 0.54 & 0.82 \\
\hline & Unclassified Lachnospiraceae & $0.04(0.00-8.7)$ & $2.0(0.46-22.6)$ & $0.05(0.00-7.1)$ & 0.42 & 0.81 \\
\hline & Ruminococcus & $0.02(0.00-1.9)$ & $0.00(0.00-0.01)$ & $0.01(0.00-1.7)$ & 0.26 & 0.69 \\
\hline & Oscillospira & $0.00(0.00-0.16)$ & $0.00(0.00-0.01)$ & $0.03(0.00-0.89)^{*}$ & 0.04 & 0.24 \\
\hline & Veillonella & $7.0(1.04-16.3)$ & $3.6(1.14-5.41)$ & $6.2(1.57-29.7)$ & 0.53 & 0.82 \\
\hline & Unclassified Enterobacteriaceae & $27.7(10.1-45.2)$ & $34.9(13.1-74.7)$ & $30.5(10.8-47.8)$ & 0.79 & 0.86 \\
\hline & Akkermansia & $0.00(0.00-0.01)$ & $0.00(0.00-0.00)$ & $0.00(0.00-0.01)$ & 0.36 & 0.81 \\
\hline \multirow[t]{2}{*}{ Caesarean, emergency } & & $49(45.4 \%)$ & $10(9.3 \%)$ & $49(45.4 \%)$ & & \\
\hline & Bifidobacterium & $6.5(1.2-18.0)$ & $4.8(1.9-12.4)$ & $5.3(0.18-16.8)$ & 0.75 & 0.86 \\
\hline
\end{tabular}


Table 3 Relative abundance of dominant genera in faecal microbiota of infants at 3-4 months, according to birth scenarios and pet exposure (Continued)

\begin{tabular}{llllll} 
Bacteroides & $0.08(0.03-0.17)$ & $0.13(0.05-17.1)$ & $0.09(0.04-1.3)$ & 0.19 & 0.61 \\
Parabacteroides & $0.00(0.00-0.01)$ & $0.01(0.00-0.02)^{*}$ & $0.00(0.00-0.01)$ & 0.05 & 0.27 \\
Streptococcus & $1.2(0.5-3.0)$ & $0.64(0.13-5.1)$ & $0.96(0.27-2.7)$ & 0.48 & 0.81 \\
Unclassified Clostridiaceae & $0.36(0.02-3.3)$ & $0.30(0.01-0.67)$ & $0.31(0.04-1.6)$ & 0.65 & 0.86 \\
Clostridium & $0.19(0.02-2.4)$ & $0.04(0.00-1.1)$ & $0.20(0.02-1.2)$ & 0.63 & 0.86 \\
Unclassified Lachnospiraceae & $0.03(0.01-5.2)$ & $0.39(0.01-1.6)$ & $0.77(0.01-9.2)$ & 0.41 & 0.81 \\
Ruminococcus & $0.00(0.00-0.03)$ & $0.00(0.00-0.33)$ & $0.22(0.00-4.6)^{* *}$ & 0.01 & 0.16 \\
Oscillospira & $0.01(0.00-0.45)$ & $0.00(0.00-1.2)$ & $0.19(0.01-2.8)^{* *}$ & 0.02 & 0.16 \\
Veillonella & $9.2(2.98-26.2)$ & $8.6(4.3-42.4)$ & $8.1(0.53-23.8)$ & 0.45 & 0.81 \\
Unclassified Enterobacteriaceae & $34.1(16.5-54.1)$ & $18.1(7.5-32.9)$ & $16.4(6.3-48.4)$ & 0.1 & 0.44 \\
Akkermansia & $0.00(0.00-0.01)$ & $0.00(0.00-0.01)$ & $0.00(0.00-0.01)$ & 0.81 & 0.86 \\
\hline
\end{tabular}

IQR interquartile range, FDR false discovery rate

Post hoc comparisons between no exposure group and either group of exposure were done by Mann-Whitney $U$ test. ${ }^{*} P<0.05$; ${ }^{* *} P<0.01$; ${ }^{* * *} P<0.0001$

${ }^{a}$ Dominant genera have overall median relative abundance $>1 \%$ at 3-4 months; phyla are in plain text and families are in italics. Comparisons by nonparametric Kruskal-Wallis test with FDR correction for multiple testing

association with leanness or lower body mass index in both infants and adults [31-35]. Members of the genus Oscillospira are highly heritable, predominate in the lean host and are positively associated with the leannesspromoting bacterium, Christensenella minuta [32]. Escober et al. [34] also reported decreasing abundance of Oscillospira with obesity in three different geographical regions, despite substantial differences in gut microbial composition. As confirmed by meta-analysis [33], the abundance of Oscillospira has also been found to be negatively associated with paediatric inflammatory bowel disease [36]. The health-promoting effects of Oscillospira are not fully understood. Unlike Ruminococcus, they are not fibre degraders but rather, produce butyrate by relying on fermentation products secreted by other bacterial species or on sugars liberated from host mucins [37]. This is supported by an elegant animal study comparing the microbiota response to fasting across different vertebrates [38]. In this study, Oscillospira were observed to be the only genus whose levels increased during fasting, indicating their ability to degrade host glycans such as fucose, sialic acids and glucuronic acid.

Members of Ruminococcus have also been detected in the stool of neonates and infants [39] but are reportedly absent in some infants delivered vaginally or by CS [40]. Like the Oscillospira, they are also present in dogs and cats [41]. The role of ruminococci in infant health is also poorly understood. Among their noticeable functions, these microbes stimulate the production and degradation of mucin [42], vital to the maintenance of an intact microbiota-mucin barrier. They are also fibre degraders [43] and predominant in formula-fed infants [44, 45]. Yet, ruminococci are still found in breastfed infants and interestingly, their colonization depends on the oligosaccharide content of breast milk [46]. Lastly, they produce ruminococcin $\mathrm{A}$, a bacteriocin which can inhibit various pathogenic species of Clostridium [47]. In our previous study within the same cohort, we observed a strong link between low levels of Ruminococcaceae and food sensitization at age 1, even after adjustment for major microbiota-disrupting events [20].

Our current study also suggests the potential for pet ownership to assist in reducing the burden of group B Streptococcus (GBS) in infants by lowering the abundance of its family, Streptococcaceae. According to a recent paper from McCloskey et al. [48], antenatal pet exposure has been linked to reduced cardiovascular risk of infants born to mothers colonized with GBS during pregnancy. In Canada and elsewhere, the major indication for providing IAP is to prevent GBS infection in newborns [49]. Within vaginally born infants with IAP, we found that prenatal pet exposure reduced the abundance of faecal Streptococcaceae; this association could not be explained by siblingship, breastfeeding status or other covariates. With mechanisms for microbe interactions to be elucidated, it is conceivable that bacteriocin produced from Ruminococcus, a microbe which was more abundant in study infants when Streptococcaceae were depleted, inhibits growth of streptococci. However, others have found lowered abundance of Oscillospira but elevated levels of Ruminococcus to co-occur with a greater abundance of Streptococcaceae at 6 months following vaginal GBS colonization in primarily formula-fed infants [50].

Under birth scenarios involving vaginal delivery, Proteobacteria became less abundant in infants with postnatal pet exposure which commenced prenatally. After emergency CS, the following changes with pet exposure were observed for Proteobacteria: reduced species 
richness, and abundance of Enterobacteriaceae and of Citrobacter. Pet exposure was also significantly associated with reduced Enterobacteriaceae among infants born vaginally without IAP but not exclusively breastfed afterwards. While our findings appear to contradict reports of greater Escherichia coli colonization in the vaginal microbiome of pregnant women who own pets [51], the timing of microbial changes in the developmental trajectory of infant microbiota is important to consider. Following vaginal delivery, Proteobacteria (especially Enterobacteriaceae) are dominant within 3 months after birth, while Bacteroidetes and Firmicutes become more prevalent as the gut microbiota matures towards an adult-like profile [52]. A bloom of Proteobacteria in the gut can indicate instability in the microbial community [53]; greater abundance (along with a higher abundance of streptococci) in 6-month-old infants has predicted future adiposity [54]. Using the $\mathrm{E} / \mathrm{B}$ ratio as an indicator for gut microbiota maturity, we previously reported that a higher ratio predicted food sensitization at age 1 [20]; in the current study, pet exposure lowered the E/B ratio in vaginally born infants exposed to IAP. Using another ratio to represent gut microbiota maturity in the current study, pet exposure was linked to a higher F/P ratio following vaginal birth in the absence of maternal IAP. Of note, Ruminococcus and Oscillospira were also elevated under these circumstances.

Additional discussion of the differential impact of pet exposure on scheduled versus emergency CS is warranted. When compared to scheduled CS, our previous study also reported a distinct microbiota profile in infants born via emergency CS, posited to be a function of the multiplicity of exposures, such as repeated antibiotic treatment and prolonged hospitalization [21]. Here, we also found a greater number of pet-associated microbial changes in infants born by emergency CS. Recurrent antibiotic exposure or hospitalization may render gut microbiota more sensitive to colonization by other microbes [55]. It is also conceivable that pet-induced changes of the maternal microbiome are transmitted to a greater extent during labour prior to an emergency CS than in the absence of labour with scheduled CS.

Our current study has several strengths, including the application of high-throughput deep sequencing to profile gut microbiota in a longitudinal population cohort, with a representative and large sample size. Predominance of Proteobacteria in gut microbiota at 3 months and its higher prevalence in CS-delivered infants were consistent with observations in other birth cohorts. Unlike other studies, our study tested the differential impact of pet exposure according to various birth modes, with the aim of providing more translational information for practitioners. Finally, we implemented statistical modelling and sensitivity analyses to explore whether observed associations were attributable to confounding covariates. On the other hand, the use of 16S rRNA sequencing in our study may have resulted in underrepresentation of organisms such as bifidobacteria. The sensitivity of this technique also did not allow identification at the species level, which is possible with highthroughput microbial culturomics [56], as well as targeted PCR or phenotypic culturing [57]. Metagenomic sequencing was not conducted, which would enable characterization of the functional properties of microbial changes with pet exposure. Since the majority of households in our study owned at least one dog, a larger sample is required to differentiate the effects of different pet species (e.g. dog and or cat) in future studies.

\section{Conclusions}

With increasing ownership of pets in our modern lifestyle and reports of their beneficial effects, the question of pet ownership is becoming a common one for pregnant women. Our findings highlighted the differential impact of pet exposure on infant gut microbiota following variant birth scenarios; however, in common, the abundance of Ruminococcus and Oscillospira were found to be increased independent of other factors. In addition, our finding of reduced streptococcal colonization with prenatal pet ownership may lower the risk for childhood metabolic and atopic disease. Further research is needed to link the pet-related microbiota changes with health outcomes of infants in the CHILD cohort, as well as in other populations.

\section{Additional files}

Additional file 1: Table S1. PERMANOVA analysis used to evaluate microbial community differences of infant gut at 3-4 months due to pet exposures following different birth scenarios. (DOCX $35 \mathrm{~kb}$ )

Additional file 2: Table S2. Effects of pet exposure on richness and diversity in infant faecal microbiota at 3-4 months. (DOCX $78 \mathrm{~kb}$ )

Additional file 3: Table S3. Richness and diversity of infant faecal microbiota at 3-4 months according to birth scenarios and pet exposure. (DOCX $146 \mathrm{~kb}$ )

Additional file 4: Table S4. Relative abundance of dominant phyla and families in faecal microbiota of infants belonged to different stratified groups, according to birth scenarios and pet exposure. (DOCX $105 \mathrm{~kb}$ )

Additional file 5: Table S5. Crude and adjusted likelihoods of microbiota measurements at 3-4 months according to birth scenarios and pet exposure episodes. (DOCX $126 \mathrm{~kb}$ )

Additional file 6: Table S6. Linear discriminant analysis (LDA) scores for differentially abundant bacterial taxa due to pet exposure in formulafed infants born by Caucasian mothers without prior direct antibiotic exposure until 3 months old following different birth scenarios $(P<0.05)$. (DOCX $54 \mathrm{~kb}$ )

Additional file 7: Figure S1. Pet exposure associated changes in gut microbiota of selected infants from Caucasian mothers with no anitobiotic exposure and no exclusi ve breastfeeding at 3 months following different birth scenarios. (PDF $839 \mathrm{~kb}$ ) 
Additional file 8: Table S7. Relative abundance of dominant genera in faecal microbiota of infants belonged to different stratified groups, according to birth scenarios and pet exposure. (DOCX $102 \mathrm{~kb}$ )

\section{Abbreviations}

CHILD: Canadian Healthy Infant Longitudinal Development; CS: Caesarean section; IAP: Intrapartum antibiotic prophylaxis

\section{Acknowledgements}

The authors would like to thank all the families who took part in this study, and the whole CHILD team, which includes interviewers, computer and laboratory technicians, clerical workers, research scientists, volunteers, managers, receptionists and nurses. Anita Kozyrskyj and James Scott will serve as the guarantors for the contents of this paper.

CHILD study investigators include Sears MR, (Director), McMaster University; Subbarao P (co-Director), The Hospital for Sick Children; Anand SS, McMaster University; Azad M, University of Manitoba; Becker AB, University of Manitoba; Befus AD, University of Alberta; Brauer M, University of British Columbia; Brook JR, University of Toronto; Chen E, Northwestern University, Chicago; Cyr M, McMaster University; Daley D, University of British Columbia; Dell S, Sick Children's Hospital; Denburg JA, McMaster University; Duan Q, Queen's University; Eiwegger T, The Hospital for Sick Children; Grasemann H, Sick Children's Hospital; HayGlass K, University of Manitoba; Hegele R, Sick Children's Hospital; Holness DL, University of Toronto; Hystad P, Oregon State University; Kobor MS, University of British Columbia; Kollmann TR, University of British Columbia; Kozyrskyj AL, University of Alberta; Laprise C, Université du Québec à Chicoutimi; Lou WYW, University of Toronto; Macri J, McMaster University; Mandhane PM, University of Alberta; Miller G, Northwestern University, Chicago; Moraes T, Sick Children's Hospital; Paré PD, University of British Columbia; Ramsey C, University of Manitoba; Ratjen F, Sick Children's Hospital; Sandford A, University of British Columbia; Scott JA, University of Toronto; Scott J, University of Toronto; Silverman F, University of Toronto; Simons E, University of Manitoba; Takaro T, Simon Fraser University; Tebbutt S, University of British Columbia; To T, Sick Children's Hospital; Turvey SE, University of British Columbia.

\section{Funding}

This research was specifically funded by the CIHR Canadian Microbiome Initiative (Grant No. 227312). The Canadian Institutes of Health Research $(\mathrm{ClHR})$ and the Allergy, Genes and Environment (AllerGen) Network of Centres of Excellence provided core support for the CHILD study. HMT holds an Alberta Innovates-Postdoctoral Fellowship in Health.

\section{Availability of data and materials}

The datasets used and/or analysed during the current study are available from the corresponding author on reasonable request.

\section{Authors' contributions}

Dr Kozyrskyj had full access to all the data in the study and takes responsibility for the integrity of the data and the accuracy of the data analysis. HMT and AK designed the study. TK, DSG and JAS carried out the amplicon sequencing. HMT and JAS performed the bioinformatics analysis, and HMT and AK performed the statistical analysis and interpretation. HMT wrote the manuscript with the input from the other authors. All authors read and approved the final manuscript.

\section{Competing interests}

The authors declare that they have no competing interests.

\section{Consent for publication}

Not applicable

\section{Ethics approval and consent to participate}

Written informed consent was obtained from parents at enrollment. This study was approved by the ethics board at the University of Alberta.

\section{Publisher's Note}

Springer Nature remains neutral with regard to jurisdictional claims in published maps and institutional affiliations.

\section{Author details}

Department of Pediatrics, University of Alberta, 3-527 Edmonton Clinic Health Academy, 11405-87th Avenue, Edmonton, AB T6G IC9, Canada. ${ }^{2}$ Dalla Lana School of Public Health, University of Toronto, Toronto, ON, Canada. ${ }^{3}$ Faculty of Health Sciences, Simon Fraser University, Burnaby, BC, Canada. ${ }^{4}$ Department of Obstetrics and Gynecology, University of Alberta, Edmonton, AB, Canada. ${ }^{5}$ Department of Agricultural, Food and Nutritional Science, University of Alberta, Edmonton, AB, Canada. ${ }^{6}$ Centre for the Analysis of Genome Evolution and Function, University of Toronto, Toronto, ON, Canada. ${ }^{7}$ Department of Pediatrics and Child Health, Children's Hospital Research Institute of Manitoba, University of Manitoba, Winnipeg, MB, Canada. ${ }^{8}$ Department of Pediatrics, Child \& Family Research Institute, BC Children's Hospital, University of British Columbia, Vancouver, BC, Canada. ${ }^{9}$ Department of Pediatrics, Hospital for Sick Children, University of Toronto, Toronto, ON, Canada. ${ }^{10}$ Department of Medicine, McMaster University, Hamilton, ON, Canada.

Received: 8 December 2016 Accepted: 14 March 2017

Published online: 06 April 2017

\section{References}

1. Backhed F. Programming of host metabolism by the gut microbiota. Ann Nutr Metab. 2011;58 Suppl 2:44-52.

2. Eckburg PB, Bik EM, Bernstein CN, Purdom E, Dethlefsen L, Sargent M, Gill $\mathrm{SR}$, Nelson KE, Relman DA. Diversity of the human intestinal microbial flora. Science. 2005;308(5728):1635-8.

3. Backhed F, Roswall J, Peng Y, Feng Q, Jia H, Kovatcheva-Datchary P, Li Y, Xia Y, Xie $\mathrm{H}$, Zhong $\mathrm{H}$, et al. Dynamics and stabilization of the human gut microbiome during the first year of life. Cell Host Microbe. 2015;17(5):690-703.

4. Adlerberth I, Wold AE. Establishment of the gut microbiota in western infants. Acta Paediatr. 2009;98(2):229-38.

5. Marques TM, Wall R, Ross RP, Fitzgerald GF, Ryan CA, Stanton C. Programming infant gut microbiota: influence of dietary and environmental factors. Curr Opin Biotechnol. 2010;21 (2):149-56.

6. Strachan DP. Hay fever, hygiene, and household size. BMJ. 1989;299(6710):1259-60.

7. Ezell JM, Wegienka G, Havstad S, Ownby DR, Johnson CC, Zoratti EM. A cross-sectional analysis of pet-specific immunoglobulin E sensitization and allergic symptomatology and household pet keeping in a birth cohort population. Allergy Asthma Proc. 2013;34(6):504-10.

8. Hesselmar B, Aberg N, Aberg B, Eriksson B, Bjorksten B. Does early exposure to cat or dog protect against later allergy development? Clin Exp Allergy. 1999;29(5):611-7.

9. Litonjua AA, Milton DK, Celedon JC, Ryan L, Weiss ST, Gold DR. A longitudinal analysis of wheezing in young children: the independent effects of early life exposure to house dust endotoxin, allergens, and pets. J Allergy Clin Immunol. 2002;110(5):736-42.

10. Lodge CJ, Allen KJ, Lowe AJ, Hill DJ, Hosking CS, Abramson MJ, Dharmage SC. Perinatal cat and dog exposure and the risk of asthma and allergy in the urban environment: a systematic review of longitudinal studies. Clin Dev Immunol. 2012;2012:176484.

11. Nermes M, Niinivirta K, Nylund L, Laitinen K, Matomaki J, Salminen S, Isolauri E. Perinatal pet exposure, faecal microbiota, and wheezy bronchitis: is there a connection? ISRN Allergy. 2013;2013:827934.

12. Ownby DR, Johnson CC, Peterson EL. Exposure to dogs and cats in the first year of life and risk of allergic sensitization at 6 to 7 years of age. JAMA. 2002;288(8):963-72.

13. Wold AE. The hygiene hypothesis revised: is the rising frequency of allergy due to changes in the intestinal flora? Allergy. 1998;53(46 Suppl):20-5.

14. Lodrup Carlsen KC, Roll S, Carlsen KH, Mowinckel P, Wijga AH, Brunekreef B, Torrent M, Roberts G, Arshad SH, Kull I, et al. Does pet ownership in infancy lead to asthma or allergy at school age? Pooled analysis of individual participant data from 11 European birth cohorts. PLoS One. 2012;7(8):e43214.

15. Havstad S, Wegienka G, Zoratti EM, Lynch SV, Boushey HA, Nicholas C, Ownby DR, Johnson CC. Effect of prenatal indoor pet exposure on the trajectory of total IgE levels in early childhood. J Allergy Clin Immunol. 2011; 128(4):880-85. e4.

16. Cassidy-Bushrow AE, Wegienka G, Havstad S, Levin AM, Lynch SV, Ownby DR, Rundle AG, Woodcroft KJ, Zoratti EM, Johnson CC. Does pet-keeping modify the association of delivery mode with offspring body size? Matern Child Health J. 2015;19(6):1426-33. 
17. Azad MB, Konya T, Maughan H, Guttman DS, Field CJ, Sears MR, Becker AB, Scott JA, Kozyrskyj AL. Infant gut microbiota and the hygiene hypothesis of allergic disease: impact of household pets and siblings on microbiota composition and diversity. Allergy, Asthma Clin Immunol. 2013;9(1):15.

18. Nermes M, Endo A, Aarnio J, Salminen S, Isolauri E. Furry pets modulate gut microbiota composition in infants at risk for allergic disease. J Allergy Clin Immunol. 2015;136(6):1688-90. e1.

19. Konya T, Koster B, Maughan H, Escobar M, Azad MB, Guttman DS, Sears MR, Becker AB, Brook JR, Takaro TK, et al. Associations between bacterial communities of house dust and infant gut. Environ Res. 2014;131:25-30.

20. Azad MB, Konya T, Guttman DS, Field CJ, Sears MR, HayGlass KT, Mandhane PJ, Turvey SE, Subbarao P, Becker AB, et al. Infant gut microbiota and food sensitization: associations in the first year of life. Clin Exp Allergy. 2015;45(3):632-43.

21. Azad MB, Konya T, Persaud RR, Guttman DS, Chari RS, Field CJ, Sears MR, Mandhane PJ, Turvey SE, Subbarao P, et al. Impact of maternal intrapartum antibiotics, method of birth and breastfeeding on gut microbiota during the first year of life: a prospective cohort study. BJOG. 2016;123(6):983-93.

22. Caporaso JG, Kuczynski J, Stombaugh J, Bittinger K, Bushman FD, Costello EK, Fierer N, Pena AG, Goodrich JK, Gordon Jl, et al. QIIME allows analysis of highthroughput community sequencing data. Nat Methods. 2010;7(5):335-6.

23. DeSantis TZ, Hugenholtz P, Larsen N, Rojas M, Brodie EL, Keller K, Huber T, Dalevi D, Hu P, Andersen GL. Greengenes, a chimera-checked $16 S$ rRNA gene database and workbench compatible with ARB. Appl Environ Microbiol. 2006;72(7):5069-72

24. Wang Q, Garrity GM, Tiedje JM, Cole JR. Naive Bayesian classifier for rapid assignment of rRNA sequences into the new bacterial taxonomy. Appl Environ Microbiol. 2007:73(16):5261-7.

25. Mariat D, Firmesse O, Levenez F, Guimaraes V, Sokol H, Dore J, Corthier G, Furet JP. The Firmicutes/Bacteroidetes ratio of the human microbiota changes with age. BMC Microbiol. 2009;9:123.

26. Laursen MF, Zachariassen G, Bahl MI, Bergstrom A, Host A, Michaelsen KF, Licht TR. Having older siblings is associated with gut microbiota development during early childhood. BMC Microbiol. 2015;15:154.

27. Molloy J, Allen K, Collier F, Tang ML, Ward AC, Vuillermin P. The potential link between gut microbiota and IgE-mediated food allergy in early life. Int J Environ Res Public Health. 2013;10(12):7235-56.

28. Azad MB, Becker AB, Guttman DS, Sears MR, Scott JA, Kozyrskyj AL. Canadian Healthy Infant Longitudinal Development Study I. Gut microbiota diversity and atopic disease: does breast-feeding play a role? J Allergy Clin Immunol. 2013; 131(1):247-8.

29. Sagheddu V, Patrone V, Miragoli F, Puglisi E, Morelli L. Infant early gut colonization by Lachnospiraceae: high frequency of Ruminococcus gnavus. Front Pediatr. 2016;4:57.

30. Million M, Tidjani Alou M, Khelaifia S, Bachar D, Lagier JC, Dione N, Brah S, Hugon P, Lombard V, Armougom F, et al. Increased Gut redox and depletion of anaerobic and methanogenic prokaryotes in severe acute malnutrition. Sci Rep. 2016;6:26051.

31. Tims S, Derom C, Jonkers DM, Vlietinck R, Saris WH, Kleerebezem M, de Vos WM, Zoetendal EG. Microbiota conservation and BMI signatures in adult monozygotic twins. ISME J. 2013;7(4):707-17.

32. Goodrich JK, Waters JL, Poole AC, Sutter JL, Koren O, Blekhman R, Beaumont M, Van Treuren W, Knight R, Bell JT, et al. Human genetics shape the gut microbiome. Cell. 2014;159(4):789-99.

33. Walters WA, Xu Z, Knight R. Meta-analyses of human gut microbes associated with obesity and IBD. FEBS Lett. 2014;588(22):4223-33.

34. Escobar JS, Klotz B, Valdes BE, Agudelo GM. The gut microbiota of Colombians differs from that of Americans. Eur Asians BMC Microbiol. 2014;14:311.

35. Verdam FJ, Fuentes S, de Jonge C, Zoetendal EG, Erbil R, Greve JW, Buurman WA, de Vos WM, Rensen SS. Human intestinal microbiota composition is associated with local and systemic inflammation in obesity. Obesity (Silver Spring). 2013;21(12):E607-15.

36. Kaakoush NO, Day AS, Huinao KD, Leach ST, Lemberg DA, Dowd SE, Mitchell HM. Microbial dysbiosis in pediatric patients with Crohn's disease. J Clin Microbiol. 2012;50(10):3258-66.

37. David LA, Maurice CF, Carmody RN, Gootenberg DB, Button JE, Wolfe BE, Ling AV, Devlin AS, Varma Y, Fischbach MA, et al. Diet rapidly and reproducibly alters the human gut microbiome. Nature. 2014;505(7484):559-63.

38. Kohl KD, Amaya J, Passement CA, Dearing MD, McCue MD. Unique and shared responses of the gut microbiota to prolonged fasting: a comparative study across five classes of vertebrate hosts. FEMS Microbiol Ecol. 2014;90(3):883-94.
39. Favier CF, Vaughan EE, De Vos WM, Akkermans AD. Molecular monitoring of succession of bacterial communities in human neonates. Appl Environ Microbiol. 2002;68(1):219-26.

40. Biasucci G, Benenati B, Morelli L, Bessi E, Boehm G. Cesarean delivery may affect the early biodiversity of intestinal bacteria. J Nutr. 2008;138(9):1796S-800S.

41. Weese JS, Jalali M. Evaluation of the impact of refrigeration on next generation sequencing-based assessment of the canine and feline fecal microbiota. BMC Vet Res. 2014;10:230.

42. Crost EH, Tailford LE, Le Gall G, Fons M, Henrissat B, Juge N. Utilisation of mucin glycans by the human gut symbiont Ruminococcus gnavus is straindependent. PLoS One. 2013;8(10):e76341.

43. Shen Q, Zhao L, Tuohy KM. High-level dietary fibre up-regulates colonic fermentation and relative abundance of saccharolytic bacteria within the human faecal microbiota in vitro. Eur J Nutr. 2012;51(6):693-705.

44. Tannock GW, Lawley B, Munro K, Gowri Pathmanathan S, Zhou SJ, Makrides M, Gibson RA, Sullivan T, Prosser CG, Lowry D, et al. Comparison of the compositions of the stool microbiotas of infants fed goat milk formula, cow milk-based formula, or breast milk. Appl Environ Microbiol. 2013;79(9):3040-8.

45. Magne F, Hachelaf W, Suau A, Boudraa G, Mangin I, Touhami M, Bouziane-Nedjadi K, Pochart P. A longitudinal study of infant faecal microbiota during weaning. FEMS Microbiol Ecol. 2006;58(3):563-71.

46. Coppa GV, Gabrielli O, Zampini L, Galeazzi T, Ficcadenti A, Padella L, Santoro L, Soldi S, Carlucci A, Bertino E, et al. Oligosaccharides in 4 different milk groups, Bifidobacteria, and Ruminococcus obeum. J Pediatr Gastroenterol Nutr. 2011; 53(1):80-7.

47. Dabard J, Bridonneau C, Phillipe C, Anglade P, Molle D, Nardi M, Ladire M, Girardin H, Marcille F, Gomez A, et al. Ruminococcin A, a new lantibiotic produced by a Ruminococcus gnavus strain isolated from human feces. Appl Environ Microbiol. 2001;67(9):4111-8.

48. McCloskey K, Vuillermin P, Carlin JB, Cheung M, Skilton MR, Tang ML, Allen K, Gilbert GL, Ranganathan S, Collier F et al. Perinatal microbial exposure may influence aortic intima-media thickness in early infancy. Int J Epidemiol. 2016 doi:10.1093/ije/dyw042.

49. van Schalkwyk J, Van Eyk N. Antibiotic prophylaxis in obstetric procedures. J Obstet Gynaecol Can. 2010;32(9):878-92.

50. Cassidy-Bushrow AE, Sitarik A, Levin AM, Lynch SV, Havstad S, Ownby DR, Johnson CC, Wegienka G. Maternal group B Streptococcus and the infant gut microbiota. J Dev Orig Health Dis. 2016;7(1):45-53.

51. Stokholm J, Schjorring S, Pedersen L, Bischoff AL, Folsgaard N, Carson CG, Chawes B, Bonnelykke K, Molgaard A, Krogfelt KA, et al. Living with cat and dog increases vaginal colonization with E. coli in pregnant women. PLoS One. 2012;7(9):e46226.

52. Matamoros S, Gras-Leguen C, Le Vacon F, Potel G, de La Cochetiere MF. Development of intestinal microbiota in infants and its impact on health. Trends Microbiol. 2013;21(4):167-73.

53. Shin NR, Whon TW, Bae JW. Proteobacteria: microbial signature of dysbiosis in gut microbiota. Trends Biotechnol. 2015;33(9):496-503.

54. Dogra S, Sakwinska O, Soh SE, Ngom-Bru C, Bruck WM, Berger B, Brussow H, Lee YS, Yap F, Chong YS et al. Dynamics of infant gut microbiota are influenced by delivery mode and gestational duration and are associated with subsequent adiposity. MBio. 2015;6(1):e02419-14.

55. Stiemsma LT, Turvey SE, Finlay BB. An antibiotic-altered microbiota provides fuel for the enteric foe. Cell Res. 2014;24(1):5-6.

56. Lagier JC, Khelaifia S, Alou MT, Ndongo S, Dione N, Hugon P, Caputo A, Cadoret F, Traore SI, Seck EH, et al. Culture of previously uncultured members of the human gut microbiota by culturomics. Nat Microbiol. 2016;1:16203.

57. Browne HP, Forster SC, Anonye BO, Kumar N, Neville BA, Stares MD, Goulding D, Lawley TD. Culturing of 'unculturable' human microbiota reveals novel taxa and extensive sporulation. Nature. 2016;533(7604):543-6. 